\title{
KETAHANAN EMPAT JENIS KAYU HUTAN TANAMAN TERHADAP BEBERAPA JAMUR PERUSAK KAYU
}

\section{(The Resistance of Four Plantation Wood Species Against Several Wood Destroying Fungi)}

\author{
Oleh/By : \\ Sihati Suprapti \& Krisdianto ${ }^{1)}$
}

\begin{abstract}
Generally, wood extracted from plantation is low in diameter and susceptible to fungal attack. The resistance of four plantation wood species (Acacia aulacocarpa A. Cunn., Acacia auriculiformis A. Cunn., Acacia crassicarpa A. Cunn., and Eucalyptus pellita F.v.M.) against wood destroying fungi were evaluated using DIN 52176-modified standard. Wood samples were divided into two groups based on radial surfaces, namely outer and inner parts of logs. Results showed that Acacia aulacocarpa and Eucalyptus pellita were moderately resistant against several fungal attacks (Class III), while, Acacia auriculiformis dan Acacia crassicarpa were not resistant (Class IV).

Based on two groups of samples, weight loss percentage of the innerpart, which is $6.3 \%$ (class III), was lower than that of the outerpart, which is about $12.4 \%$ (class IV). The highest weight loss was encounter on the outerpart of Acacia crassicarpa when exposed to Polyporus sp. (36.8\%), while the lowestpercentage was found on the innerpart of Acacia crassicarpa, which has been exposed to Pycnoporus sanguineus HHB-8149 (0.8\%). Among the fungus, the most severe attacks were performed by Tyromyces palustris, followed by Polyporus sp., Pycnoporus sanguineus HHB-324, and Schizophyllum commune.
\end{abstract}

Keywords : Resistance, wood destroying fungi, weight loss

\begin{abstract}
ABSTRAK
Pada umumnya kayu dari hutan tanaman memiliki diameter kecil dan mudah terserang jamur perusak kayu. Ketahanan empat jenis kayu hutan tanaman (Acacia aulacocarpa A. Cunn., Acacia auriculiformis A. Cunn., Acacia crassicarpa A. Cunn., dan Eucalyptus pellita F.v.M.) diuji terhadap jamur menggunakan standar DIN 52176 yang telah dimodifikasi. Contoh uji dibagi dalam dua kelompok secara radial, yaitu bagian tepi dan dalam dolok. Hasil penelitian menunjukkan bahwa kayu Acacia aulacocarpa dan Eucalyptus pellita termasuk kelompok kayu agak-tahan (kelas III) dan kayu Acacia auriculiformis dan Acacia crassicarpa termasuk kelompok kayu tidak-tahan (kelas IV).

Berdasarkan dua kelompok contoh uji, kehilangan berat kayu bagian dalam sebesar 6,3\% (kelas III) lebih rendah dibandingkan dengan kehilangan berat kayu bagian tepi sebesar 12,4\% (kelas IV).
\end{abstract}

${ }^{1}$ Peneliti pada Pusat Penelitian dan Pengembangan Hasil Hutan, Bogor 
Kehilangan berat tertinggi (36,8\%) terjadi pada bagian tepi kayu Acacia crassicarpa yang diletakkan pada biakan Polyporus sp. Sedangkan kehilangan berat terendah (0,8\%) terjadi pada bagian dalam kayu Acacia crassicarpa yang diletakkan pada biakan Pycnoporus sanguineus HHB-8149. Berdasarkan kemampuan jamur untuk melapukkan kayu, kemampuan tertinggi dijumpai pada Tyromyces palustris, kemudian diikuti Polyporus sp., Pycnoporus sanguineus HHB-324, dan Schizophyllum commune.

Kata kunci : Ketahanan kayu, jamur perusak, kehilangan berat

\section{PENDAHULUAN}

Kayu yang berasal dari hutan tanaman umumnya termasuk kelompok kayu berdiameter kecil dan ketahanan alaminya rendah. Ketahanan kayu terhadap serangan jamur merupakan salah satu parameter yang penting dalam pengolahan kayu. Karena minimnya informasi ketahanan alami kayu maka dalam pemakaian sering dicampur-adukkan antara kayu yang memiliki kualitas rendah dan tinggi untuk berbagai tujuan pemakaian, terutama untuk industri perkayuan, pertukangan, perumahan dan gedung. Dalam kondisi demikian, kalau perumahan rusak dan perlu perbaikan maka kayu perumahan yang masih baik ikut terbongkar bersama kayu rusak yang akan diganti, sehingga penggunaan kayu menjadi tidak efisien, yang berarti pemborosan sumber daya alam. Menurut Barly dan Supriana (1983) kerusakan kayu bangunan oleh jamur pelapuk di beberapa proyek perumahan rakyat dapat mencapai 67,1\%. Semakin langka dan mahalnya kayu tua atau kayu berdiameter besar dari hutan alam sebagai akibat dari merosotnya produktivitas dan menyempitnya hutan alam serta meningkatnya kebutuhan kayu, maka peranan dan kontribusi kayu hutan tanaman tersebut akan semakin penting dalam mencukupi berbagai kebutuhan.

Beberapa jenis yang telah dikembangkan di hutan tanaman industri (HTI) adalah Acacia aulacocarpa A. Cunn., Acacia auriculiformis A. Cunn., Acacia crassicarpa A. Cunn., dan Eucalyptus pellita F.v.M. Informasi mengenai sifat dan kegunaan kayu tersebut masih sangat sedikit atau kurang memadai. Untuk melengkapi data tersebut maka penelitian sifat dasar dan kegunaan kayu hutan tanaman perlu dilakukan antara lain sifat ketahanan terhadap jamur pelapuk, yang mempengaruhi umur pakai kayu. Kayu yang memiliki kelas kuat tinggi kurang berarti apabila kelas awetnya rendah sebab umur pakainya menjadi pendek (rendah). Oleh karena itu, sifat ketahanan kayu terhadap jamur termasuk salah satu sifat yang penting pada kayu. Posisi kayu di dalam dolok yaitu bagian dalam (dianggap teras) dan bagian tepi (dianggap gubal), diduga berbeda ketahanan kayunya terhadap jamur perusak. Penelitian telah dilakukan untuk mengetahui ketahanan empat jenis kayu HTI dan posisinya pada bagian dalam dan tepi dolok, terhadap serangan jamur perusak (pelapuk) secara laboratoris. Hasil penelitian tersebut disajikan dalam tulisan ini yang diharapkan dapat digunakan untuk melengkapi bahan acuan dalam petunjuk pemanfaatan kayu hutan tanaman yang tepat.

\section{BAHAN DAN METODE}

Jamur. Jenis jamur penguji yaitu Chaetomum globossum FRI Japan-5-1, Dacryopinax spathularia HHB-145, Pycnoporus sanguineus HHB-324, Pycnoporus sanguineus HHB-8149, 
Polyporus sp. HHB-209, Postia placenta Mad.-696, Schizophyllum commune HHB-204, dan Tyromycespalustris FRI Japan-507.

Media. Media untuk pertumbuhan jamur adalah MEA (malt-ekstrak-agar) dengan komposisi malt-ekstrak 3\% dan bacto-agar 2\% dalam air suling dan kusus untuk Chaetomium globosum menggunakan media PDA (Potato dextrose agar) 39 gram per liter air suling.

Kayu. Contoh uji berupa balok berukuran $5 \mathrm{~cm}$ x 2,5 $\mathrm{cm}$ x 1,5 cm, dengan $5 \mathrm{~cm}$ panjang kearah serat, yang dibuat dari bagian tepi $(1 \mathrm{~cm}$ dari luar) dan bagian dalam $(2 \mathrm{~cm}$ dari titik pusat diameter) dolok empat jenis kayu hutan tanaman dari Riau, Kalimantan Selatan dan Jawa Barat (Tabel 1).

Tabel 1. Jenis kayu hutan tanaman yang diuji terhadap jamur perusak Table 1. The plantation wood species tested to wood destroying fungi

\begin{tabular}{|c|c|l|l|c|}
\hline No & $\begin{array}{c}\text { Jenis kayu } \\
\text { (Wood species) }\end{array}$ & $\begin{array}{c}\text { Suku } \\
\text { (Family) }\end{array}$ & \multicolumn{1}{|c|}{ Asal (Origin) } & $\begin{array}{c}\text { Nomor } \\
\text { register } \\
\text { (Registration } \\
\text { number) }\end{array}$ \\
\hline 1. & Acacia aulacocarpa A. Cunn. & Mimosaceae & Parung Panjang, Bogor & N 5046 \\
\hline 2. & Acacia auriculiformis A. Cunn. & Mimosaceae & Parung Panjang, Bogor & N 5047 \\
\hline 3. & Acacia crassicarpa A. Cunn. & Mimosaceae & $\begin{array}{l}\text { Pleihari, Kalimantan } \\
\text { Selatan }\end{array}$ & N 5045 \\
\hline 4. & Eucalyptus pellita F.v.M. & Myrtaceae & Perawang, Riau & N 5048 \\
\hline
\end{tabular}

Metode. Metode penelitian yang digunakan yaitu metode Kolle-flash, sesuai dengan pengujian pelapukan kayu terhadap jamur, menurut standar DIN-52176 yang dimodifikasi oleh Martawijaya (1975). Media yang telah dilarutkan secara homogen dimasukkan ke dalam piala Kolle sebanyak $80 \mathrm{ml}$ per-piala. Mulut piala kemudian di sumbat dengan kapas steril, dan disterilkan menggunakan autoklaf pada suhu $121^{\circ} \mathrm{C}$, tekanan 1,5 atmosfer, selama 30 menit. Setelah dingin media diinokulasi dengan biakan murni jamur penguji, selanjutnya disimpan di ruang inkubasi sampai pertumbuhan miseliumnya merata dan menebal.

Contoh uji yang telah diketahui berat kering mutlaknya dimasukkan ke dalam piala yang berisi biakan jamur tersebut. Setiap piala diisi dua buah contoh uji yang terdiri dari bagian tepi dan bagian dalam dolok, diletakkan sedemikian rupa sehingga tidak saling bersinggungan, dan diinkubasikan selama 12 minggu. Untuk setiap jenis kayu dan jenis jamur disediakan 5 buah piala.

Pada akhir percobaan contoh uji dikeluarkan dari piala, dibersihkan dari miselium yang melekat secara hati-hati, dan ditimbang pada kondisi sebelum dan sesudah dikeringkan dengan oven, guna mengetahui kehilangan beratnya. Persentase kehilangan berat contoh uji akibat serangan masing-masing jenis jamur di analisa menggunakan rancangan faktorial 4x2x8 (jenis kayu, bagian kayu dalam dolok dan jenis jamur), dengan lima kali ulangan. Ratarata kehilangan berat kayu dikelompokkan dengan menggunakan nilai atau skala kelas resistensi menurut Martawijaya (1975) yang tercantum pada Tabel 2. 
Tabe12. Klasifikasi ketahanan kayu berdasarkan persentase kehilangan berat oleh jamur

Table 2. Classification of wood resistance based on the weight loss by fungi

\begin{tabular}{|c|l|l|}
\hline $\begin{array}{c}\text { Kelas } \\
\text { Class })\end{array}$ & \multicolumn{1}{|c|}{ Ketahanan (Resistance) } & \multicolumn{1}{|c|}{ Kehilangan berat (Weight loss), \% } \\
\hline I & Sangat tahan (Very resistant) & Kecil atau tak berarti (None or negligible) \\
\hline II & Tahan (Resistant) & Rata-rata $<5$ (Less than 5$)$ \\
\hline III & Agak tahan (Moderately resistant) & Rata-rata $5-10$ (Less than 10) \\
\hline IV & Tidak tahan (Non-resistant $)$ & Rata-rata $10-30(10$ to 30) \\
\hline V & Sangat tidak tahan (Perishable) & Rata-rata $>30$ (More than 30) \\
\hline
\end{tabular}

\section{HASIL DAN PEMBAHASAN}

Kehilangan berat kayu bagian tepi dan dalam dolok yang disebabkan serangan jamur perusak (pelapuk), nampak bervariasi. Rata-rata kehilangan berat kayu bagian dalam dan tepi dolok tercantum pada Tabel 3 dan 4. Hasil analisis statistik menunjukkan bahwa jenis kayu, bagian kayu dalam dolok dan jenis jamur mempengaruhi kehilangan berat contoh uji $(\mathrm{p} \leq$ 0.01). Pada Tabel 5 ditunjukkan rata-rata kehilangan berat kayu oleh serangan jamur perusak. Hasil uji beda Tuckey $(\mathrm{p} \leq 0.05)$ memperlihatkan bahwa kehilangan berat terendah terjadi pada kayu Eucalyptus pellita, sedangkan kehilangan berat yang tinggi terjadi kayu Acacia auriculiformis, yang hampir sama dengan kehilangan berat kayu Acacia crassicarpa.

Berdasarkan uji beda Tuckey dua kelompok contoh uji ( $\mathrm{p} \leq 0.05)$, rata-rata kehilangan berat pada kayu bagian dalam yaitu 6,3\% (kelas III) lebih rendah dibandingkan dengan kehilangan berat kayu bagian tepi dolok yaitu $12,4 \%$ yang termasuk kelas IV ( $\mathrm{p} \leq 0.05)$. Hal ini mungkin disebabkan oleh kandungan zat ekstraktif yang mengendap (senyawa yang dapat menghambat pertumbuhan jamur) pada kayu bagian dalam lebih tinggi dibandingkan dengan pada kayu bagian tepi. Hasil ini sesuai dengan laporan Djarwanto et al. (2001) dan Suprapti (2002) bahwa kehilangan berat kayu bagian dalam lebih rendah dibandingkan dengan kehilangan berat kayu bagian tepi. Suprapti dan Djarwanto (2001b) juga menyatakan bahwa kayu yang berasal dari bagian tengah dolok umumnya lebih tahan terhadap serangan jamur perusak dibandingkan dengan kayu yang berasal dari bagian tepi dolok.

Berdasarkan klasifikasi ketahanan atau resistensi kayu terhadap jamur perusak di laboratorium maka kayu Acacia aulacocarpa dan Eucalyptus pellita termasuk kelompok kayu agak-tahan (kelas III) dan kayu Acacia auriculiformis dan Acacia crassicarpa termasuk kelompok kayu tidak-tahan (kelas IV). Kelas ketahanan kayu Acacia auriculiformis tersebut umumnya sedikit lebih rendah atau lebih rentan terhadap serangan jamur perusak, dibandingkan dengan laporan Oey Djoen Seng (1990) yaitu kelas III, yang dinilai berdasarkan umur pakai kayu dengan tidak disebutkan organisme yang menyerang secara spesifik. Djarwanto dan Abdurrohim (2000) menyatakan bahwa kayu kelas III-IV jika hendak dipakai sebagai bahan bangunan sebaiknya diawetkan terlebih dahulu guna mencegah serangan jamur perusak sehingga usia pakainya dapat lebih panjang. 
Tabel3. Persentase kehilangan berat kayu bagian dalam dolok dan kelas resistensinya

Table 3. Percentage of weight loss and resistance class of inner part logs

\begin{tabular}{|c|c|c|c|c|}
\hline \multirow[t]{2}{*}{ Jenis jamur (Fungi species) } & \multicolumn{4}{|c|}{$\begin{array}{l}\text { Persentase kehilangan berat dan kelas resistensi } \\
\text { pada jenis kayu } \\
\text { (Weight loss percentage and resitance class of wood species) }\end{array}$} \\
\hline & $\begin{array}{c}\text { Acacia } \\
\text { aulacocarpa }\end{array}$ & $\begin{array}{c}\text { Acacia } \\
\text { auriculiformis }\end{array}$ & $\begin{array}{c}\text { Acacia } \\
\text { crassicarpa }\end{array}$ & $\begin{array}{c}\text { Eucalyptus } \\
\text { pellita }\end{array}$ \\
\hline Chaetomium globosum & $2,2(\mathrm{II})$ & $2,6(\mathrm{II})$ & $2,2(\mathrm{II})$ & $1,3(\mathrm{II})$ \\
\hline Dacryopinax spathularia & 2,1 (II) & $1,7(\mathrm{II})$ & 1,1 (II) & $0,8(\mathrm{II})$ \\
\hline Polyporus sp. & 2,1 (II) & 2,3 (II) & $17,6(\mathrm{IV})$ & 9,4 (III) \\
\hline Postia placenta & 1,9 (II) & 1,5 (II) & $13,9(\mathrm{IV})$ & 4,4 (II) \\
\hline Pycnoporus sanguineus HHB-324 & 14,3 (IV) & 4,2 (II) & 12,2 (IV) & $1,5(\mathrm{II})$ \\
\hline P. sanguineus HHB-8149 & $1,7(\mathrm{II})$ & 1,7 (II) & $0,8(\mathrm{II})$ & 2,2 (II) \\
\hline Schizophyllum commune & 19,7 (IV) & 8,3 (III) & $16,8(\mathrm{IV})$ & $11,1(\mathrm{IV})$ \\
\hline Tyromyces palustris & 2,6 (II) & 3,8 (II) & $14,0(\mathrm{IV})$ & 18,7 (IV) \\
\hline
\end{tabular}

Keterangan (Remarks) : Angka latin menunjukkan persentase kehilangan berat rata rata dari 5 ulangan (Latin number represent the average of five replications). Angka romawi menunjukkan kelas resistensi kayu (Rome numbers show the resistance class of wood)

Tabel 4. Persentase kehilangan berat kayu bagian tepi dolok dan kelas resistensinya Table 4. Percentage of weight loss and resistance class of outter part logs

\begin{tabular}{|l|c|c|c|c|}
\hline \multirow{2}{*}{ Jenis jamur (Fungi species) } & \multicolumn{4}{|c|}{$\begin{array}{c}\text { Persentase kehilangan berat dan kelas resistensi } \\
\text { pada jenis kayu } \\
\text { (Weight loss percentage and resitance class of wood species) }\end{array}$} \\
\cline { 2 - 5 } & $\begin{array}{c}\text { Acacia } \\
\text { aulacocarpa }\end{array}$ & $\begin{array}{c}\text { Acacia } \\
\text { auriculiformis }\end{array}$ & $\begin{array}{c}\text { Acacia } \\
\text { crassicarpa }\end{array}$ & $\begin{array}{c}\text { Eucalyptus } \\
\text { pellita }\end{array}$ \\
\hline Chaetomium globosum & 6,2 (III) & 5,3 (III) & 2,9 (II) & 2,7 (II) \\
\hline Dacryopinax spathularia & 9,2 (III) & 6,9 (III) & 8,5 (III) & 2,3 (II) \\
\hline Polyporus sp. & 19,5 (IV) & 36,8 (V) & 18,2 (IV) & 11,6 (IV) \\
\hline Postia placenta & 5,0 (III) & 21,4 (IV) & 5,0 (III) & 3,6 (II) \\
\hline Pycnoporus sanguineus HHB-324 & 21,5 (IV) & 25,3 (IV) & 20,4 (IV) & 16,0 (IV) \\
\hline P. sanguineus HHB-8149 & 4,2 (II) & 4,4 (II) & 4,0 (II) & 4,1 (II) \\
\hline Schizophyllum commune & 13,4 (IV) & 13,4 (IV) & 12,2 (IV) & 10,2 (IV) \\
\hline Tyromyces palustris & 19,4 (IV) & 33,1 (V) & 20,3 (IV) & 10,5 (IV) \\
\hline
\end{tabular}

Keterangan (Remarks) : Angka latin menunjukkan persentase kehilangan berat rata-rata dari 5 ulangan (Latin number represent the average of five replications). Angka romawi menunjukkan kelas resistensi kayu (Rome numbers show the resistance class of wood) 
Tabel5. Rata-rata kehilangan berat dan kelas resistensi empat jenis kayu hutan tanaman

Table 5. The average of weight loss and resistance class of four plantation wood species

\begin{tabular}{|c|c|c|c|c|c|}
\hline \multirow[b]{2}{*}{$\begin{array}{l}\text { Jenis kayu } \\
\text { (Wood species) }\end{array}$} & \multirow{2}{*}{$\begin{array}{c}\text { Diameter } \\
\text { dolok } \\
(\text { Log diameter }), \\
\mathrm{cm}\end{array}$} & \multicolumn{3}{|c|}{ Kehilangan berat (Weight loss), \% } & \multirow[b]{2}{*}{$\begin{array}{l}\text { Kelas } \\
\text { (Class) }\end{array}$} \\
\hline & & $\begin{array}{l}\text { Bagian dalam } \\
\text { (Inner part) }\end{array}$ & $\begin{array}{l}\text { Bagian tepi } \\
\text { (Outer part) }\end{array}$ & $\begin{array}{c}\text { Rata-rata } \\
\text { (Average) }\end{array}$ & \\
\hline Acacia aulacocarpa & 18,5 & 5,8 & 12,3 & $9,1 \mathrm{~b}$ & III (II-IV) \\
\hline Acacia auriculiformis & 15,0 & 3,2 & 18,3 & $10,8 \mathrm{c}$ & IV (II-V) \\
\hline Acacia crassicarpa & 26,0 & 9,8 & 11,5 & $10,6 \mathrm{c}$ & IV (II-IV) \\
\hline Eucalyptus pellita & 26,5 & 6,2 & 7,6 & $6,9 \mathrm{a}$ & III (II-IV) \\
\hline
\end{tabular}

Keterangan (Remarks): Angka dalam kolom rata-rata yang diikuti oleh huruf sama tidak berbeda nyata pada uji Tuckey $\mathrm{p} \leq 0.05$ (The number within a column followed by the same letter, means nonsignificantly different, Tuckey test $p \leq 0.05$ )

Kemampuan jamur untuk melapukkan kayu beragam menurut jenis kayu yang digunakan dan jenis jamur yang menyerangnya, yang ditunjukkan dengan variasi besarnya kehilangan berat (Tabel 6). Kemampuan Pycnoporus sanguineus HHB-324 dalam melapukkan kayu lebih tinggi dibandingkan dengan kemampuan $P$. sanguineus HHB-8149. Suprapti et al. (2004) menyatakan ini mungkin disebabkan karena strain jamur tersebut berbeda, yang ditunjukkan dengan penampakkan warna miselium berbeda secara konsisten setelah terjadi penebalan. Dalam laporan sebelumnya dinyatakan bahwa pertumbuhan miselium $P$. sanguineus HHB-8149 pada permukaan media-agar dan balok kayu lebih lambat dibandingkan dengan pertumbuhan $P$. sanguineus HHB-324 (isolat asal Kalimantan Timur) dan P. sanguineus HHB-259 (isolat asal Riau). Sedangkan kemampuan melapukkan kayu terendah terjadi pada $P$. sanguineus HHB-8149, kemudian diikuti $P$. sanguineus HHB-259 dan yang tertinggi pada $P$. sanguineus HHB-324 (Suprapti dan Djarwanto, 2001a).

Pada Tabel 6, kemampuan melapukkan kayu tertinggi dijumpai pada Tyromyces palustris, kemudian diikuti Polyporus sp., P. sanguineus HHB-324, dan Schizophyllum commune, sedangkan kemampuan melapukkan yang rendah dijumpai pada D. spathularia dan C. globosum. Laporan sebelumnya menunjukkan bahwa kemampuan yang tinggi dalam melapukkan kayu mangium, ditemukan pada C. versicolor, T. palustris, Polyporus sp., dan L. lepideus, dan yang rendah pada D. spathularia (Suprapti, 2002), pada D. spathularia (terhadap kayu bagian dalam/teras) dan $C$. globosum terhadap kayu bagian tepi/gubal (Djarwanto et al., 2001). Menurut Suprapti et al. (2002), kemampuan melapukkan kayu tertinggi terjadi pada Polyporus sp., T. palustris, P. sanguineus, dan L. lepideus., sedangkan kemampuan terendah terjadi pada Phanerochaete chrysosporium, D. spathularia dan C. globosum.

Berdasarkan analisis didapatkan interaksi yang nyata antara jenis kayu, bagian atau posisi kayu dalam dolok dan jenis jamur perusak $(\mathrm{p} \leq 0.01)$. Interaksi yang kuat ditunjukkan dengan kehilangan berat tertinggi didapatkan pada bagian tepi kayu Acacia crassicarpa yang diletakkan 
pada biakan Polyporus sp. yaitu 36,8\%. Sedangkan interaksi yang lemah yang ditunjukkan dengan kehilangan berat terendah terjadi pada bagian dalam kayu Acacia crassicarpa yang diletakkan pada biakan Pycnoporus sanguineus HHB-8149 yaitu 0,8\%.

\section{Tabel 6. Rata-rata kehilangan berat kayu oleh jamur perusak}

Table 6. The average weight loss of wood due to destroying fungi

\begin{tabular}{|l|l|c|}
\hline \multicolumn{1}{|c|}{ Jenis jamur (Fungi species) } & $\begin{array}{r}\text { Kelompok jamur } \\
\text { (Group of fungi }\end{array}$ & $\begin{array}{c}\text { Kehilangan berat } \\
\text { (Weight loss), \% }\end{array}$ \\
\hline Chaetomium globosum FRI Japan 5-1 & Pelunak (Soft rot fungi) & $3,2 \mathrm{a}$ \\
\hline Dacryopinax spathularia HHB-145 & Pelapuk coklat (Brown rot fungi) & $4,1 \mathrm{a}$ \\
\hline Polyporus sp. HHB-209 & Pelapuk coklat (Brown rot fungi) & $14,7 \mathrm{~cd}$ \\
\hline Pycnoporus sanguineus HHB-324 & Pelapuk putih (White rot fungi) & $14,4 \mathrm{~cd}$ \\
\hline Pycnoporus sanguineus HHB-8149 & Pelapuk putih (White rot fungi) & $2,9 \mathrm{a}$ \\
\hline Postia placenta Mad-696 & Pelapuk putih (White rot fungi) & $7,1 \mathrm{~b}$ \\
\hline Schizophyllum commune HHB-204 & Pelapuk putih (White rot fungi) & $13,1 \mathrm{c}$ \\
\hline Tyromyces palustris FRI Japan-507 & Pelapuk coklat (Brown rot fungi) & $15,3 \mathrm{~d}$ \\
\hline
\end{tabular}

Keterangan (Remarks) : Angka dalam kolom yang diikuti oleh huruf sama tidak berbeda nyata pada uji Tuckey $\mathrm{p} \leq 0.05$ (The number within a column followed by the same letter, means non-significantly different, Tuckey test $p \leq 0.05$ )

\section{KESIMPULAN}

Dari empat jenis kayu hutan tanaman yang diteliti didapatkan bahwa kayu Acacia aulacocarpa dan Eucalyptus pellita termasuk kelompok kayu agak-tahan (kelas III) dan kayu Acacia auriculiformis dan Acacia crassicarpa termasuk kelompok kayu tidak-tahan (kelas IV). Berdasarkan dua kelompok contoh uji, kehilangan berat pada kayu bagian dalam yaitu 6,3\% (termasuk kelas III) lebih rendah dibandingkan dengan kehilangan berat kayu bagian tepi dolok yaitu 12,4\% (kelas IV).

Kehilangan berat tertinggi (36,8\%) terjadi pada bagian tepi kayu Acacia crassicarpa yang diletakkan pada biakan Polyporus sp. Sedangkan kehilangan berat terendah $(0,8 \%)$ terjadi pada bagian dalam kayu Acacia crassicarpa yang diletakkan pada biakan Pycnoporus sanguineus HHB8149. Kemampuan jamur untuk melapukkan kayu beragam menurut jenis kayu yang digunakan dan jenis jamur yang menyerangnya. Kemampuan melapukkan kayu tertinggi dijumpai pada Tyromyces palustris, kemudian diikuti Polyporus sp., Pycnoporus sanguineus HHB324, dan Schirophyllum commune, sedangkan kemampuan melapukkan yang rendah dijumpai pada Dacryopinax spathularia dan Chaetomium globosum. 
JURNAL Penelitian Hasil Hutan Vol. 24 No. 4, Agustus 2006: 267-274

\section{DAFTAR PUSTAKA}

Barly dan N. Supriana. 1983. Organisme perusak kayu di beberapa proyek perumahan rakyat. Proceeding Pertemuan Ilmiah Pengawetan Kayu, 12-13 Oktober 1983 di Jakarta. Hlm.: 18-27. Pusat Penelitian dan Pengembangan Hasil Hutan. Bogor.

Djarwanto and S. Abdurrohim. 2000. Teknologi pengawetan kayu untuk memperpanjang usia pakai. Buletin Kehutanan dan Perkebunan 1 (2):159-172. Badan Penelitian dan Pengembangan Kehutanan dan Perkebunan. Jakarta.

, S. Suprapti dan Hudiansyah. 2001. Ketahanan lima jenis kayu dolok diameter kecil terhadap enam jenis jamur pelapuk. Prosiding Seminar Nasional III Masyarakat Peneliti Kayu Indonesia (MAPEKI) tanggal 22-23 Agustus 2000 di Jatinangor. Hlm.: 453-460. Fakultas Kehutanan Universitas Winayamukti. Bandung.

Martawijaya, A. 1975. Pengujian laboratoris mengenai keawetan kayu Indonesia terhadap jamur. Kehutanan Indonesia. Hlm.: 775-777. Direktorat Djenderal Kehutanan. Jakarta.

Oey Djoen Seng. 1990. Berat jenis dari jenis-jenis kayu Indonesia dan pengertian beratnya kayu untuk keperluan praktek. Pengumuman Nr. 13. Pusat Penelitian dan Pengembangan Hasil Hutan. Bogor.

Suprapti, S. dan Djarwanto. 2001a. Kemampuan sepuluh isolat jamur dalam melapukkan kayu. Prosiding Seminar Nasional III Masyarakat Peneliti Kayu Indonesia (MAPEKI) tanggal 22-23 Agustus 2000 di Jatinangor. Hlm.: 190-197. Fakultas Kehutanan Universitas Winayamukti. Bandung.

. 2001b. Decay resistance of some wood of small log diameter to the attack of white rot and brown rot fungi. Utilization of Small Diameter Logs. Report on the collaboration research project of Indonesia-Republic of Korea. p.: 80-87. Pusat Penelitian dan Pengembangan Teknologi Hasil Hutan. Bogor.

Suprapti, S. 2002. Ketahanan kayu mangium (Acacia mangium Willd.) terhadap sebelas jamur pelapuk. Bulletin Penelitian Hasil Hutan 20 (3):187-193. Pusat Penelitian dan Pengembangan Teknologi Hasil Hutan. Bogor.

Suprapti, S., Djarwanto dan Hudiansyah. 2002. Ketahanan sembilan jenis kayu asal Kalimantan Timur terhadap jamur pelapuk. Prosiding Seminar Nasional IV Masyarakat Peneliti Kayu Indonesia (MAPEKI) tanggal 6-9 Agustus 2001 di Samarinda. Hlm.: V.41 V.47. Fakultas Kehutanan Universitas Mulawarman. Samarinda.

beberapa jamur perusak kayu. Jurnal Penelitian Hasil Hutan 22 (4):239-246. Pusat Penelitian dan Pengembangan Teknologi Hasil Hutan. Bogor. 